\title{
The Predicaments of Independent College P.E Teachers and the Countermeasure
}

\author{
Youfeng Wang ${ }^{1,}$, ${\text { Lidao } \mathrm{Li}^{1}}^{1}$ \\ ${ }^{1}$ Oxbridge College, Kunming University of Science and Technology, Kunming, Yunnan, China \\ a444044391@qq.com
}

Keywords: Independent College p.e Teachers; Predicaments; Countermeasure.

\begin{abstract}
Under the trend of new curriculum reform, sport teaching has been regarded. As independent college P.E teachers, they not only equip the fundamental P.E subject knowledge, but also break through current predicaments, making sure they could improve the comprehensive quality of P.E teaching. From present conditions, high school P.E teachers have multiple character features, thus they could rouse student to accept knowledge automatically by P.E teaching, and strengthen their sports quality. However, according to the situation, independent college P.E teachers still face predicaments in personal development because of bearing heavy workload in their daily teaching, which turns out effects their health and comprehensive quality of teaching quality. For those independent college P.E teachers, they should confirm current predicaments and combine the sports teaching situation in the new period to explore acceptable measurements.
\end{abstract}

\section{Introduction}

In the respect of P.E teachers, they should clear and definite the fundamental purpose of sports teaching, and improve it by combining teaching situations. While stepped into the stage of new curriculum reform, independent college P.E teachers usually face the heavy workloads: they not only carry daily sports teaching liability, but also pay their attention to students' sports comprehensive quality, employing various ways to improve professionalism. For most of sports teachers, it is essential to accept moderate career pressure that turns out their motivation for new curriculum, exploring a more suitable new teaching mode to students' characteristic [1]. However, most of sports teachers face predicaments, and if they could not break through it, it will hinder the whole improvements of teaching quality. Therefore, they should face their predicament and explore breakthroughs of it. While coping with predicaments, sports teachers should suit their measure to local condition and explore a more suitable teaching method.

\section{The concrete performance of predicaments}

Under present trend, plenty of sports teachers feel like themselves has sunk into the predicaments because of heavy career pressure. Our society lacks fine cognition for sports teacher, in such situations, they suffer heavier workloads. At the same time, schools also not offer a corresponding treatment to those sports teachers. And that is the reason why their vocational laziness happens frequently. While stepped into the transferring state, sports teacher often face dilemma and lashes, which easily cause a situation that some teachers will avoid daily teaching and scientific research [2]. However, if they could make a moderate change when facing predicament, it will transform into a vital motivation for them to improve their comprehensive quality. According to present situation, independent college P.E teachers usually face following predicaments:

Ignorance Of Physical Scientific Research. From the daily teaching of independent college, the point of sports teaching still focus on students' final exam marks. For a long term, college will combine the final exam performance and teaching evaluation as an index while evaluate the effect of course, which ignore the deep contents of scientific research. Influenced by teaching evaluation, sports teachers thus pay all their attentions to daily teaching than to scientific research. Meanwhile, it is hard for them to accomplish their scientific research from busy daily teaching plan. For most 
students, teachers require them equip excellent competitive skills and ignore their comprehensive physical quality [3]. Hence one can see that plenty of sports teachers do not explore the deep spiritual corn of P.E course, and hold an ignorance attitude to scientific research. In the aspect of scientific research, many sports teacher don't acquire enough fund supports, which easily causes a stagnation of academic ability. In the long-term, it lacks a fine career prospect for P.E teachers.

Lack of self-improvement Consciousness. Sports teacher from inside of college often lack essential motivation of self-improvement and consciousness. Often, colleges will offer a steady salary and extra treatments, thus in this steady circumstance, part of teachers lack consciousness of self- improvement and self-development. While coping with daily teaching, most physical teachers are tend to just deal with teaching rather than pay more attentions, they are in a passive position. Influenced by such passive situation, their physical teaching will also be affected. Thus most of them are content with things as they are, they lack the consciousness of self-improvement; though some of them achieve self-improvement, the motivation of it is to acquire degree or meet the requirement of college. Influenced by such utilitarian consciousness, it is hard for physical teacher to aspire inside studying motive power, they have lower thirst for knowledge and also held a passive attitude of self-improvement. In the long-term, in is hard for P.E teacher to acquire comprehensive improvements [4.

Defects of interpersonal communications. In the aspect of interpersonal communication, most of sports teaching teachers lack such multiple interpersonal communications, thus it is hard for them to solve the inter-relationship appropriately. While building the relationship net, some of them do it improperly with colleagues and superiors, and under this situations, it is difficult to reflect their daily teaching information in time. As for teaching plan, P.E teachers also ignore the timely assignment of it. Once there are conflicts with colleagues, they must concerning about job promotion or evaluation of professional titles, and it will influence the harmony between colleagues if solve these improperly. With such negative attitude, some P.E teachers will finish their daily teaching in a psychological inversion. Fundamentally, the lack of interpersonal communication will hinder P.E teachers' promotion and self-development, and it is not good for building a community.

The lower job security and salary. Recent years, new curriculum reform is advancing rapidly, more and more school give a certain attention to students' physical situation. Under the premise of health, P.E teaching is placed in a important positions [5]. In today's society, people suffer heavier daily pressure, thus they need healthy body, and for student groups, it should be first to strong their bodies. P.E course plays important role while shaping the healthy body, but the salary and other treatment of P.E teachers are not promoted together. And inside the college, the class fees of P.E teachers and formal teachers are not same, the former haven't acquire formation and job security. Because of lacking essential material encouragement, many P.E teachers give up their enthusiasm for teaching and scientific researches. Therefore, colleges should offer a more perfect job security to these P.E teachers and, they could save excellent stuff by promoting the salary to build a high quality teaching team.

\section{The resource of predicament}

First of all, because of influenced by traditional consciousness, both students and teachers all pay more attentions to the major courses than to P.E course. Practically, the P.E course should be the fundamental subject. Only have a strong body, could students finish their study. However, because of lacking this fundamental subject, many P.E teachers stepped in a predicament and think they are not treated highly [6]. Most of teachers and students think that if students could learn their majority well and get excellent marks, it means they make their study successful. However, once they out of school and step into society for fierce competition, they usually make an overdraft of health. And if they could not make a strong base of their physical situation, it will be hard for them to adapt them to fierce social competition. From it, we can find that the fundamental resource for predicament is these P.E teachers and the whole society lack consciousness that sports teaching owns vital value.

Secondly, colleges never concern the inner demand of P.E teachers, lacking consciousness of fine salary. Under the examination situations, P.E is regarded as vice subject which been ignored for a 
long term [7]. In the just-finishing mind, many colleges will occupy the time of sports course, using its timing for other subject which turns out an unfair atmosphere of P.E teachers when doing the annual evaluations. As for them, they could not acquire equal salary and treatment as other teachers, although they pay equal or more efforts for students. Because of unequal treatment, P.E teachers still in a unbalanced mood, and they could not keep a excellent attitude into daily teaching. Meanwhile, colleges seldom concern the P.E teachers when they offer promotion or advancing chances for other teachers, which cause a long term unfair treatment for them.

Furthermore, many students also lack physical exercise and they ignore the essential of it to their health, which also cause a predicament for those P.E teachers. In the class, most of students hold a just-passing attitude, thinking once earn the credits of it they could pass the exam, and they will finish the task. Under such condition, there is indifferent and repressive atmosphere in the sports course, and the relationship between teachers and students also cold, lacking a intimate communication and interaction. In the sports course, teaching just teaching the basic theory and then ask students to imitate some motivations. Course lack such creations will lead a bored atmosphere and it is hard for building a friendship between teachers and students. With the requirement of new curriculum, P.E teachers will be at a loss what to do and how to cultivate the interests of them, thus comes a strong anxiety inside them. And because they could not adjust it, the sports teaching in independent colleges also step in to a dilemma, both teachers and students have class passively.

What's more, compared with other teachers, P.E teachers should own better physical conditions since they border heavier workload. However, with the age growing, they will find that their physical quality declines [8]. Teachers who work with a long-term P.E teaching, it will cause a absolute physical and mind loads, while other subjects operate indoors and P.E teaching usually proceeding outdoors. Compared with younger P.E teachers, those who are older present a languid condition, and cannot do a sophisticated example movement to students and guide them. Because of particularity of P.E course, psychological gap will be more vivid as their age growing, it is also inappropriate for them to solve formal teaching while disaffection caused with what treatment they get.

\section{To explore the measurements}

It can't be denied that in present new curriculum reform, P.E teacher do trap in the predicament. However it also doesn't mean they have to carry this forever, only when we affirm what predicament these independent college P.E teachers facing that we could chose a suitable measurement. In detail, while facing professional predicament, independent P.E teaches should apply following measurement:

To promote consciousness of self-improvement. The point to rid of predicament is to complete consciousness which could raise P.E teachers' progress attitude by promoting self-improvement. From the aspects of colleges, they should offer more encouragement for P.E teachers, in order to raise the pursuit for self-progress inside their mind. Once P.E teachers confirm their career orientation and aim in each stage, it is essential for them to make a blueprint of future to assure their responsibility. While facing the whole tendency of new curriculum, colleges also need to offer essential guidance for them, let them know the value of it. Under the premise of thinking their predicament, P.E teachers should promote the practicability of teaching, trying to make an intimate interaction with students. Meanwhile, colleges also should offer proper training for them to promote their self-improvement, and it will suit the conception of new curriculum reform [9].

To design a fair system of promotion and reward. As for rewarding, it is essential that colleges should offer equal salary to P.E teachers, and correct their attitude gap by material encourage. While evaluating professional titles, colleges should stay fair and indifferent. Meanwhile, they also need to offer more supports for scientific research to P.E teachers, which will let them pay more attention to a deep research, and in return improve teaching quality. When evaluating annual excellent teachers, colleges should set a comprehensive evaluation index to make teachers feel fairness of it. Therefore, they will be more positive in daily teaching [10]. As an important part of teacher team, they should recognize their own importance and try to shorten the gap with others, improving class quality. 
An intimate communications between teachers and students. While trying to rid of predicament, P.E teachers should pay more attentions to the communication with their students. Once teaching, it is need for P.E teachers to understand the demands of students' physical exercise, and on the base of it, try to communicate with students and strong it. Only both of them make an intimate cooperation and full communication, P.E course will be less tense and depress. Therefore, teachers and students will know newly of P.E course in such relaxing atmosphere. To complete interactions between teachers and students will be good for P.E teachers to solve their predicaments, and using a new attitude towards P.E course. By the way of intimate interaction, teachers and students could be friends and then teachers could improve teaching plan when understanding their students, affirming the plan will suit their demands.

To be ready of injury prevention. Because P.E class equips vivid opening feature, it is inevitable to get hurt when doing kind of sport items. From it we find that injury prevention should be the corn part in P.E course, and if we make a fine injury prevention, it will reduce the max possibility of being hurt in P.E course, and the safe risk as well [11]. Once colleges, students and whole society support that, changing their consciousness, and P.E teachers could understand their present predicament by it, then they could figure out a way to solve it. Meanwhile P.E teachers also need to explore experience, and try to rid of the worse attitude which bothers them.

\section{Summary}

P.E teachers of independent colleges often face an outstanding predicament, which came from a heavier physical and mind burden. Influenced by predicament, P.E teachers not only need to adjust themselves, but also get the acceptance from colleges, students and society. While facing predicament, teachers should keep a fine working attitude, and soothe workload in daily teaching, being grave to the new curriculum reform. They need to. Meanwhile, P.E teachers should explore a new idea to break through predicament, cultivating excellent professional quality to show their ability. However, they still face their predicament and need to explore the experience and measurement. To rid of predicament will be good to colleges and teachers, which means they could cultivate comprehensive and practicing sports people.

\section{References}

[1] Wang Man. The Professional Dilemma and Coping Strategies of Physical Education Teachers [J]. Journal of Inner Mongolia Normal University (EDUCATION SCIENCE EDITION),2014 (10):163-164.

[2] Sun Yunqiao. Analysis and Countermeasures of College Physical Education Teachers' Occupational Stress [J]. China Adult Education;,2012 (17):101-102.

[3] Luo Wenyu. Research on the status quo of physical education teachers' Career Plateau and the Countermeasures [J]. Sports world (Academic Edition),2012 (03):41-42.

[4] Fu Yi. The causes and Countermeasures of the professional plateau phenomenon of P.E teachers from primary and middle school in Tai Yuan city[J]. Journal of Jilin Institute of Physical Education,2012 (03):123-125.

[5] Fu Yi,Yu Fang,Li Gang. On the Characteristics and Strategies of College Physical Education Teachers' Career Plateau [J]. Journal of Capital Institute of Physical Education,2012 (04):40-44+67.

[6] Jia Haitao. Female Physical Education Teachers' Professional Difficulties and Coping Strategy[J]. Journal of Yichun University,2012 (08):139-140+165.

[7] Ma Hongquan. Study on Coping Strategies of Vocational College Physical Education Teachers' Burnout [J]. Modern Education Science,2012 (S1):191+196. 
[8] He Erqing. Physical Education Teachers' Job Burnout and Coping Strategies [J]. Journal of Jilin Normal University (NATURAL SCIENCE EDITION),2012 (02):112-115.

[9] Wang Jing, Liu Haijun, Chen Jin. The Negative Influence and Countermeasures of Middle School PE Teachers' Job Burnout [J]. Journal of Zhantong Teachers'College,2011 (05):59-61.

[10] Zhang Ning. A Study on the Present Situation and Countermeasures of Physical Education Teachers' Career Plateau [J]. Journal of Ningxia University (NATURAL SCIENCE EDITION),2011 (04):431-434.

[11] Ren Yong, Liu Zhengguo. Analysis and Strategy of Physical Education Teachers' Job Burnout [J]. Journal of Shandong Sport University,2012 (01):94-96. 